\title{
Applications of One-Step Environmentally-Friendly Fermentation Method to Produce Fumaric Acid with Immobilized Rhizopus arrhizus in Stirred-Tank Reactor
}

\begin{abstract}
Yuchen Ning, Yang Li, Shijie Zhao, Huan Liu,* Li Deng,* and Fang Wang
The traditional two-step cultivation mode for fungal cultivation is commonly divided into the seed stage (usually 24 to $48 \mathrm{~h}$ ) and the production stage (usually 96 to $144 \mathrm{~h}$ ). The use of two stages prolongs the total production cycle and generates excess wastewater. In this work, an efficient and environmentally friendly one-step fermentation method was applied for the production of fumaric acid by immobilized Rhizopus arrhizus in a stirredtank reactor. The nitrogen source content and the agitation speed of the reactor were optimized as the two critical factors in the one-step fermentation process; the fumaric acid production of $51 \mathrm{~g} / \mathrm{L}$ with a yield of $0.42 \mathrm{~g} / \mathrm{g}$ glucose was comparable with the product from the traditional twostep fermentation process. Furthermore, the total production cycle was shortened to $96 \mathrm{~h}$, and the amount of wastewater was reduced due to the avoidance of the seed culture process. Thus, utilization of the one-step fermentation method to produce fumaric acid was shown to be preferable feasibility and environmental-friendliness. This is a promising method for industrial production of fumaric acid and other high-value biochemicals by fungus.
\end{abstract}

Keywords: Fumaric acid; One-step fermentation; Two-stage regulation of agitation speed; Rhizopus arrhizus; Stirred-tank reactor

Contact information: Beijing Bioprocess Key Laboratory, State Key Laboratory of Chemical Resource Engineering, Beijing University of Chemical Technology, Beijing, 100029, PR China;

*Corresponding authors: liuhuan@mail.buct.edu.cn; dengli@mail.buct.edu.cn

\section{INTRODUCTION}

Given the aggravation of the environmental degradation and resource shortage, the development of environmentally friendly methods to produce clean energy is paramount (Fan et al. 2020). Fumaric acid, an important four-carbon dicarboxylic acid, is an intermediate in the TCA cycle, and it is a building block to synthesize more complex compounds in the chemical, food processing, agriculture, and pharmaceutical industries (Guo et al. 2020). Microbial fermentation using renewable biomass as raw material has the advantages of being environmentally friendly and sustainable (Abo et al. 2019; Liu et al. 2020). Rhizopus, Saccharomyces cerevisiae, Torulopsis glabrata, Escherichia coli, and their derivatives have been evaluated for their production capability of fumaric acid. Rhizopus is the most promising potential strain in industrial production due to its strong accumulation capacities of fumaric acid (Troiano et al. 2020).

To improve fumaric acid accumulation by Rhizopus, investigations have been carried out involving low-cost feedstock, isolation of high-performance strains, optimization of cultivation conditions, and mycelia morphology (Ilica et al. 2019). Few studies have paid attention to updating the cultural mode of Rhizopus. Currently, a twostep cultivation mode (divided into seed culture stage and fermentation stage) was utilized 
in Rhizopus cultivation process by controlling different carbon/nitrogen ratios in seed and fermentation media. Sufficient cells are obtained in the seed culture stage with abundant nitrogen sources supplied, while nitrogen limitation in the production stage prevents the overgrowth of cells, leading to fumaric acid accumulation (Ding et al. 2011). Nevertheless, the residual seed culture broth (containing $4 \mathrm{~g} / \mathrm{L}$ glucose, $3 \mathrm{~g} / \mathrm{L}$ fumaric acid, and $5 \mathrm{~g} / \mathrm{L}$ ethanol) is treated as waste after cultivation, which is a cost burden and a waste of water resources. A novel and superior culture is needed to alleviate these problems.

According to recent work, Rhizopus could be also used to produce lactic acid, and a convenient and economical one-step fermentation strategy has been applied to replace the conventional two-step fermentation of Rhizopus, which conducts the seed and fermentation culture stages together and leads to an increasing in lactic acid concentration and productivity (Fu et al. 2016, 2018). In this study, a similar one-step fermentation method was utilized to avoid generating excess waste water and to improve the efficiency of fumaric acid production by Rhizopus arrhizus in the stirred-tank reactor.

\section{EXPERIMENTAL}

\section{Microorganism and Culture Medium}

The strain used in this work was $R$. arrhizus $R H-7-13-9 \#$, which was cultured on an agar medium and stored at $4{ }^{\circ} \mathrm{C}$ (Liu et al. 2015). The medium used in one-step cultivation process contained $90 \mathrm{~g} / \mathrm{L}$ glucose, peptone content optimized (1.0, 1.5, 2.0, 2.5 , 3.0, 3.5 and $4.0 \mathrm{~g} / \mathrm{L}), 0.6 \mathrm{~g} / \mathrm{L} \mathrm{KH}_{2} \mathrm{PO}_{4}, 0.5 \mathrm{~g} / \mathrm{L} \mathrm{MgSO}_{4} \cdot 7 \mathrm{H}_{2} \mathrm{O}, 1.76 \times 10^{-3} \mathrm{~g} / \mathrm{L} \mathrm{ZnSO}_{4} \cdot 7 \mathrm{H}_{2} \mathrm{O}$, and $4.98 \times 10^{-4} \mathrm{~g} / \mathrm{L} \mathrm{FeSO}_{4} \cdot 7 \mathrm{H}_{2} \mathrm{O}$. In addition, $50 \mathrm{~g} / \mathrm{L} \mathrm{CaCO}_{3}$ and $0.2 \%$ (v/v) soybean oil were used as the neutralizer and antifoaming agent, respectively; these were added into the stirred tank reactor after cultivated for $24 \mathrm{~h}$.

\section{One-Step Fermentation Process}

Mycelia immobilized fermentation was utilized for fumaric acid production in the one-step fermentation. Loofah fiber (prepared from dried Luffa cylindrica and purchased at Jinhua in the Zhejiang Province, China) was shown to be an available carrier for $R$. arrhizus RH-7-13-9\# in the authors' previous work (Liu et al. 2017). Small loofah fiber cubes of 0.5 to $1 \mathrm{~cm}^{3}$ were prepared, and $6.5 \mathrm{~g} / \mathrm{L}$ loofah fiber cubes were added into a $5 \mathrm{~L}$ stirred-tank reactor as mycelia immobilized carriers. $R$. arrhizus $R H-7-13-9 \#$ spores were inoculated as described previously (Liu et al. 2018b), as the ratio of $1 \%$ (v/v) into the $3 \mathrm{~L}$ medium. The one-step fermentation process was conducted at $30^{\circ} \mathrm{C}, 200 \mathrm{rpm}$, and $2.0 \mathrm{vvm}$ for $108 \mathrm{~h}$.

\section{Analytical Methods}

A high-performance liquid chromatograph (HPLC; Shimadzu Corporation, Kyoto, Japan) equipped with a refractive index detector and UV detector $(210 \mathrm{~nm})$ was utilized to detect the titer of fumaric acid, by-product ethanol, and glucose consumption. The column used was a Bio-Rad Aminex HPX-87 H ion exclusion column (Richmond, CA, USA), and $0.005 \mathrm{M} \mathrm{H}_{2} \mathrm{SO}_{4}$ was used as eluent at $50{ }^{\circ} \mathrm{C}$ with a flow rate of $0.6 \mathrm{~mL} / \mathrm{min}$ (Liu et al. 2018a). Due to the low solubility of fumaric acid and calcium fumarate, both accumulated as precipitated in the broth. To detect the total production of fumaric acid, the precipitates were dissolved in $1 \mathrm{M} \mathrm{HCl}$ (W $\mathrm{W}_{1}$ (Zhang et al. 2015). The concentration of fumaric acid in broth was recorded as $\mathrm{C}_{1}$, and the volume of residual broth was recorded as $\mathrm{V}$. The total 
fumaric acid production $\left(\mathrm{C}_{\mathrm{t}}\right)$ was calculated as the sum of the content in both precipitates and broth parts, as in Eq. 1.

$$
C_{t}=\frac{C_{1} V+W_{1}}{V}
$$

The initial glucose addition content was recorded as $\left(W_{2}\right)$, and the yield of fumaric acid $(Y)$ was calculated as shown in Eq. 2.

$$
Y=\frac{C_{t} V}{W_{2}}
$$

After fermentation, the carriers with mycelium were washed with deionized water three times and dried at $50{ }^{\circ} \mathrm{C}$ to a constant weight. The biomass content was determined by subtracting the weight of carriers.

\section{RESULTS AND DISCUSSION}

\section{Development of the One-Step Fermentation Method}

In two-step cultivation, the seed culture broth is usually discarded as waste. It was suspected that the waste seed culture broth could be reused in the fermentation stage. In this work, one-step fermentation was investigated to complete the seed and production phases synchronously by immobilized $R$. arrhizus in the stirred-tank reactor. The one-step medium contained $90 \mathrm{~g} / \mathrm{L}$ glucose with $4 \mathrm{~g} / \mathrm{L}$ peptone as initial carbon and nitrogen sources to cultivate $R$. arrhizus RH 7-13-9\#. The mycelia were clearly observed and immobilized on the carriers. The biomass reached $9.89 \mathrm{~g} / \mathrm{L}$ after spore inoculum inoculated for $24 \mathrm{~h}$, which was similar to the previous results (Xing et al. 2020). This result indicated that the growth of the strain was not impacted by the high-concentration glucose, which is necessary for fumaric acid production using one-step fermentation.

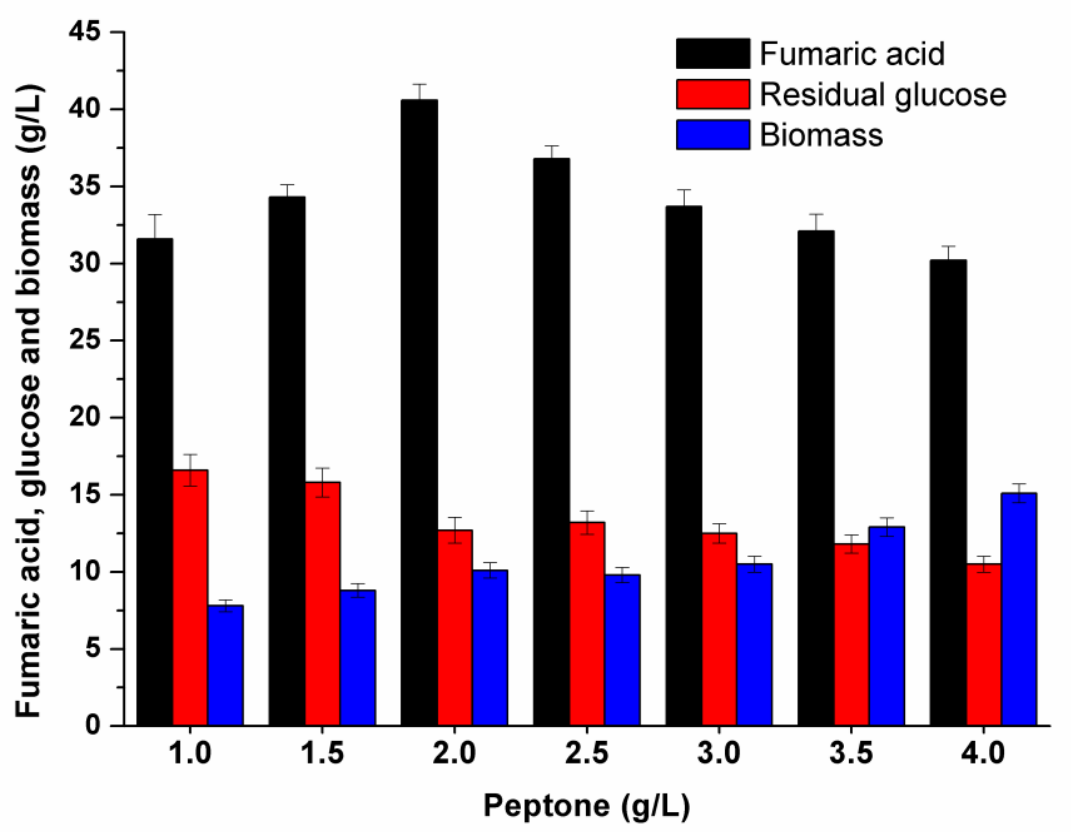

Fig. 1. One-step fermentation profiles under different peptone content 


\section{Optimization of Nitrogen Source Level in the One-Step Fermentation}

In traditional two-step fermentation, the nitrogen source is the critical factor for fumaric acid production (Xing et al. 2020). Therefore, the level of nitrogen source peptone was optimized for one-step fermentation. The production of fumaric acid, consumption of glucose, and biomass were analyzed after cultivation for $84 \mathrm{~h}$. As shown in Fig. 1, more than $30 \mathrm{~g} / \mathrm{L}$ fumaric acid was produced in the nitrogen content optimization process, which illustrated that one-step fermentation had preferable implementation ability for fumaric acid production by immobilized $R$. arrhizus $\mathrm{RH}$ 7-13-9\# in the stirred-tank reactor. The biomass displayed a gradually increasing trend with the increase of nitrogen source, which was similar to the previous results (Zhang et al. 2015). For the accumulation of fumaric acid, $40.6 \mathrm{~g} / \mathrm{L}$ fumaric acid as the highest production was obtained when $2.0 \mathrm{~g} / \mathrm{L}$ peptone was used as the nitrogen source. Either higher or lower peptone content was not favored for fumaric acid accumulation. This result was related to the balance between cell growth and fumaric acid synthesis. Limited nitrogen does not satisfy cell growth requirements and leads to low fumaric acid production; high nitrogen content causes the overgrowth of cells and has a negative effect on the transferring of oxygen and nutrients, resulting in the waste of carbon flux and decreased fumaric acid accumulation (Zhang et al. 2015). Therefore, 2 $\mathrm{g} / \mathrm{L}$ peptone was the optimum level of nitrogen source in one-step fermentation.

\section{Two-Stage Regulation of Agitation Speed in the Stirred-Tank Reactor}

In addition to the nitrogen source, the agitation speed of the stirred-tank reactor is important in fumaric acid production. A higher agitation speed destroys the growth of the cells due to the shear force, while a lower agitation speed influences the oxygen transfer and inhibits the accumulation of fumaric acid (Fu et al. 2010; Liu et al. 2017). Therefore, different agitation speeds are applied in the seed culture phase (200 rpm) and fumaric acid production phase (400 rpm) during two-step fermentation (Singh et al. 2021; Wu et al. 2018). In this study, the agitation speed was maintained at $200 \mathrm{rpm}$ throughout the onestep fermentation process, which possibly limited the accumulation of fumaric acid. To enhance fumaric acid production, the two-stage regulation of agitation speed strategy was developed for one-step fermentation, in which the agitation speed was controlled at 200 rpm in the first stage and then increased to $400 \mathrm{rpm}$ in the second stage.

The maintenance time of the first stage was critical in this strategy, and it was optimized as shown in Table 1. When the maintenance time of the first stage was $12 \mathrm{~h}$, the highest production of fumaric acid was $31.3 \mathrm{~g} / \mathrm{L}$ at $108 \mathrm{~h}$ without any precipitates formed. It was suspected that the strain could not grow well due to the short maintenance time of the first stage, while the high agitation speed $400 \mathrm{rpm}$ in the second stage was not conducive to cell growth, which resulted in the low biomass and poor production.

Table 1. Optimization of the Two-Stage Regulation of Agitation Speed

\begin{tabular}{|c|c|c|c|c|c|}
\hline $\begin{array}{c}\text { Maintenance } \\
\text { Time of the } \\
\begin{array}{c}\text { First Stage } \\
(\mathrm{h})\end{array}\end{array}$ & $\begin{array}{c}\text { Fumaric Acid } \\
\text { in Solid } \\
\text { Precipitate } \\
(\mathrm{g})\end{array}$ & $\begin{array}{c}\text { Total } \\
\text { Production of } \\
\text { Fumaric Acid } \\
(\mathrm{g} / \mathrm{L})\end{array}$ & $\begin{array}{c}\text { Yield of } \\
\text { Fumaric Acid } \\
\text { from Glucose } \\
(\mathrm{g} / \mathrm{g})\end{array}$ & $\begin{array}{c}\text { Highest } \\
\text { Production } \\
\text { of Ethanol } \\
(\mathrm{g} / \mathrm{L})\end{array}$ & $\begin{array}{c}\text { Biomass } \\
(\mathrm{g} / \mathrm{L})\end{array}$ \\
\hline 12 & 0 & 31.3 & 0.26 & $4.76 \pm 0.35$ & 8.32 \\
\hline 24 & $31.32 \pm 1.21$ & 51.0 & 0.42 & $7.81 \pm 0.43$ & 10.21 \\
\hline 36 & $24.31 \pm 0.97$ & 43.5 & 0.36 & $10.23 \pm 0.61$ & 13.34 \\
\hline 48 & $21.19 \pm 0.93$ & 41.2 & 0.34 & $16.74 \pm 0.65$ & 15.15 \\
\hline
\end{tabular}


The maintenance time of the first stage was extended so that the biomass gradually increased. However, even though the long maintenance time of the first stage was beneficial for cell growth, the high biomass resulted in more by-product ethanol, which affected the allocation of carbon flows and the production of fumaric acid.

The optimum maintenance time of the first stage was $24 \mathrm{~h}$. As shown in Fig. 2, the first stage was within $24 \mathrm{~h}$, and the agitation speed was controlled at $200 \mathrm{rpm}$, which was then regulated to $400 \mathrm{rpm}$ to switch to the second stage for fumaric acid production. When the agitation speed was increased to $400 \mathrm{rpm}$ after $24 \mathrm{~h}$, both fumaric acid accumulation and glucose consumption rates were expedited. The highest titer of fumaric acid in broth reached $36.9 \mathrm{~g} / \mathrm{L}$ at $96 \mathrm{~h}$, and $31.32 \mathrm{~g}$ fumaric acid was obtained from the precipitates at the same time. After measuring the volume of residual broth, the total fumaric acid production was calculated, and it was $51 \mathrm{~g} / \mathrm{L}$ with a yield of $0.42 \mathrm{~g} / \mathrm{g}$ glucose, which was increased by $26 \%$ compared with the production without the two-stage regulation of agitation speed. Meanwhile, the accumulation of by-product ethanol was controlled, and its highest tier was $7.81 \mathrm{~g} / \mathrm{L}$. These data illustrated that fumaric acid production could be significantly promoted through two-stage regulation of agitation speed in the one-step fermentation process. The production of fumaric acid was higher than that obtained from two-step fermentation under the same conditions (Xing et al. 2020).

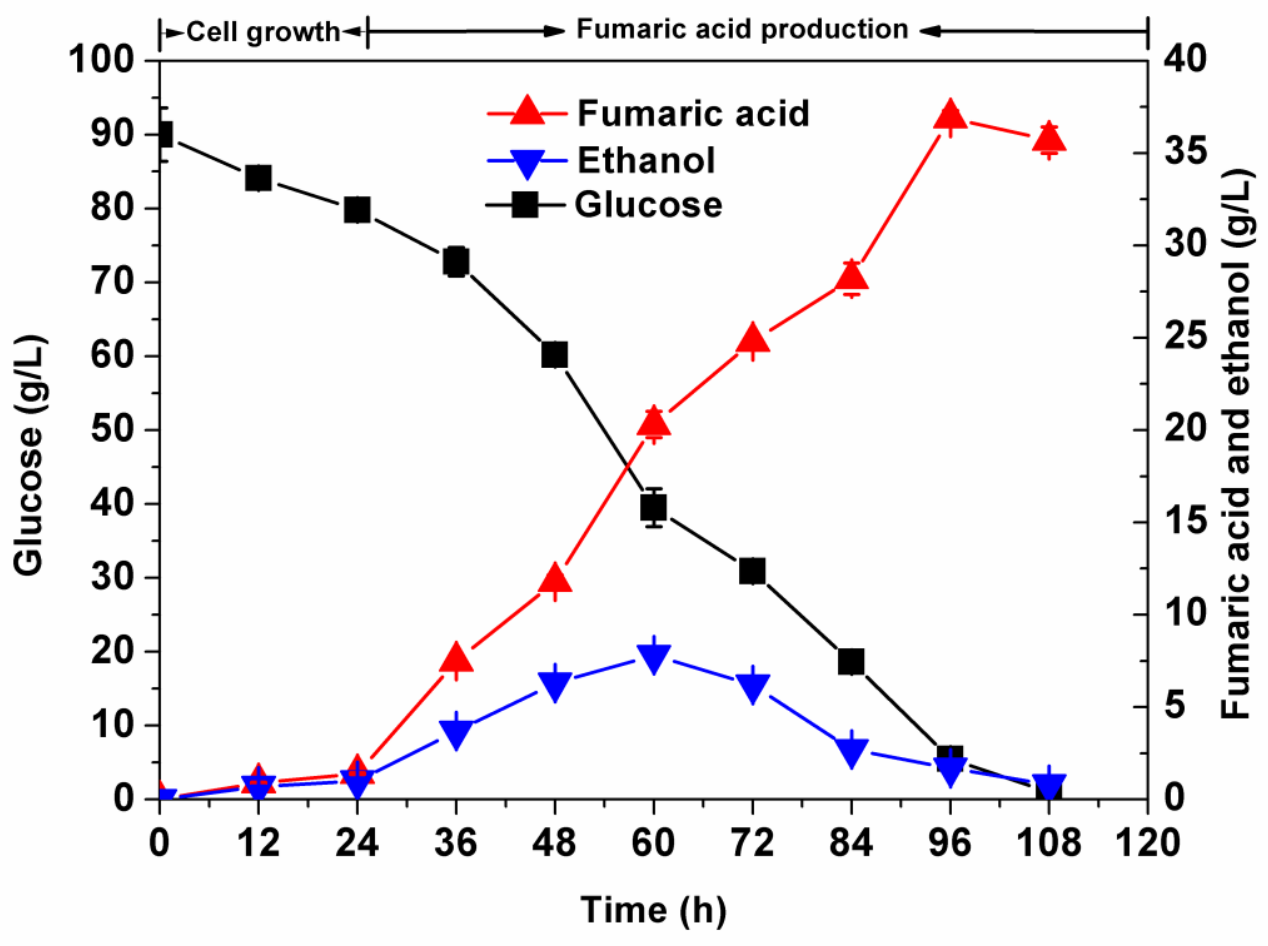

Fig. 2. Fumaric acid production profile using two-stage regulation of agitation speed in one-step fermentation process

In two-step fermentation, the seed culture stage is usually 24 to $48 \mathrm{~h}$, and then Rhizopus cells are transferred into the fermentation medium for fumaric acid production for 96 to $144 \mathrm{~h}$ (Kowalczyk et al. 2018; Swart et al. 2020). In this process, not only the total production cycle is long (about 120-192 h), but also copious wastewater is produced after the seed culture stage. In this work, the one-step fermentation method was developed, so that the total production cycle was shortened to $96 \mathrm{~h}$ and the amount of waste water was 
reduced due to the avoidance of the seed culture stage. The fumaric acid production was comparable between the one-step fermentation and the traditional two-step fermentation process (Fu et al. 2010; Singh et al. 2021). The results demonstrated that one-step fermentation had preferable feasibility, economical efficiency, and environmentalfriendliness. The effective application of the method provided a promising and potential way for industrial production of fumaric acid as well as other high-value biochemical by fungus.

\section{CONCLUSIONS}

1. In this work, the one-step fermentation method was applied to fumaric acid production by immobilized Rhizopus arrhizus in the stirred-tank reactor.

2. Nitrogen source content and the agitation speed of the reactor were optimized as the two critical factors in one-step fermentation. The optimum level of nitrogen source was $2 \mathrm{~g} / \mathrm{L}$ peptone, and the two-stage regulation of agitation speed strategy was developed to promote fumaric acid accumulation.

3. The highest fumaric acid production reached $51 \mathrm{~g} / \mathrm{L}$ with a yield of $0.42 \mathrm{~g} / \mathrm{g}$ glucose, which was comparable with the level of traditional two-step fermentation. The production cycle was shortened, and the amount of wastewater was efficiently reduced, which demonstrated the great advantages and application potential of the one-step fermentation method.

\section{ACKNOWLEDGMENTS}

This research was financially supported by National Key research program (2016YFD0400601), National Natural Science Foundation of China (21978019), China postdoctoral science foundation (2019M660420), Petro China Innovation Foundation (H2018415), the Amoy Industrial Biotechnology R\&D and Pilot Conversion Platform (3502Z20121009).

\section{REFERENCES CITED}

Abo, B. O., Gao, M., Wang, Y., Wu, C., Wang, Q., and Ma, H. (2019). "Production of butanol from biomass: Recent advances and future prospects," Environ. Sci. Pollut. $R$ 4, 1-19. DOI: 10.1007/s11356-019-05437-y

Ding, Y.Y., Li, S., Dou, C., Yu, Y., and Huang, H. (2011). "Production of fumaric acid by Rhizopus oryzae: Role of carbon-nitrogen ratio," Appl. Biochem. Biotechnol. 164(8), 1461-1467. DOI: 10.1007/s12010-011-9226-y

Fan, T., Liu, X., Zhao, R., Zhang, Y., Liu, H., Wang, Z., Wang, F., Nie, K., and Deng, L. (2020). "Hydrolysis of food waste by hot water extraction and subsequent Rhizopus fermentation to fumaric acid," J. Environ. Manage. Arcticle no. 110954.

Fu, Y.-Q., Li, S., Chen, Y., Xu, Q., Huang, H., and Sheng, X.-Y. (2010). "Enhancement of fumaric acid production by Rhizopus oryzae using a two-stage dissolved oxygen control strategy," Appl. Biochem. Biotechnol. 162(4), 1031-1038. DOI: 
10.1007/s12010-009-8831-5

Fu, Y., Sun, X., Zhu, H., Jiang, R., Luo, X., and Yin, L. (2018). “An optimized fed-batch culture strategy integrated with a one-step fermentation improves 1-lactic acid production by Rhizopus oryzae," World J. Microb. Biot. 34(6). DOI: 10.1007/s11274018-2455-2

Fu, Y.Q., Yin, L.F., Zhu, H.Y., and Jiang, R. (2016). "High-efficiency l-lactic acid production by Rhizopus oryzae using a novel modified one-step fermentation strategy," Bioresour. Technol. 218, 410-7. DOI: 10.1016/j.biortech.2016.06.127

Guo, F., Wu, M., Dai, Z., Zhang, S., Zhang, W., Dong, W., Zhou, J., Jiang, M., and Xin, F. (2020). "Current advances on biological production of fumaric acid," Biochem. Eng. J. 153, 107397. DOI: 10.1016/j.bej.2019.107397

Ilica, R.-A., Kloetzer, L., Galaction, A.-I., and Caşcaval, D. (2019). "Fumaric acid: Production and separation," BiotechnolLett 41(1), 47-57. DOI: 10.1007/s10529-0182628-y

Kowalczyk, S., Komoń-Janczara, E., Glibowska, A., Kuzdraliński, A., Czernecki, T., and Targoński, Z. (2018). "A co-utilization strategy to consume glycerol and monosaccharides by Rhizopus strains for fumaric acid production," AMB Express 8(1), 1-8. DOI: 10.1186/s13568-018-0601-8

Liu, H., Wang, W., Deng, L., Wang, F., and Tan, T. (2015). "High production of fumaric acid from xylose by newly selected strain Rhizopus arrhizus RH 7-13-9\#," Bioresour. Technol. 186(0), 348-350. DOI: 10.1016/j.biortech.2015.03.109

Liu, H., Zhao, S., Jin, Y., Yue, X., Deng, L., Wang, F., and Tan, T. (2017). "Production of fumaric acid by immobilized Rhizopus arrhizus RH 7-13-9\# on loofah fiber in a stirred-tank reactor," Bioresour. Technol. 244, 929-933. DOI:

10.1016/j.biortech.2017.07.185

Liu, H., Song, R., Liang, Y., Zhang, T., Deng, L., Wang, F., and Tan, T. (2018a). "Genetic manipulation of Escherichia coli central carbon metabolism for efficient production of fumaric acid," Bioresour. Technol. 270, 96-102. DOI: 10.1016/j.biortech.2018.08.024

Liu, H., Zhang, S., Yu, N., Dou, L., Deng, L., Wang, F., and Tan, T. (2018b). "Direct utilization of non-pretreated hydrolytic liquid of dried distiller's grains with solubles for bio-ethanol by Rhizopus arrhizus RH 7-13-9\#," Appl. Biochem. Biotechnol. 1-7. DOI: $10.1007 / \mathrm{s} 12010-018-2716-4$

Liu, H., Huang, X., Xiao, Q., Yu, Y., Deng, L., and Wang, F. (2020). "Production of cellulase by Microbulbifer hydrolyticus through co-fermentation of glucose and xylose from lignocellulose," Bioresources 15(4), 8689-8695. DOI: 10.15376/biores.15.4.8689-8695

Singh, K., Sharma, D., and Mishra, A. (2021). "Mahua flowers (Madhuca sp.) utilization as a carbon-rich natural substrate for the cost-effective bench-scale production of fumaric acid," SN Applied Sciences 3(1), 1-11. DOI: 10.1007/s42452-021-04176-5

Swart, R. M., Le Roux, F., Naude, A., De Jongh, N. W., and Nicol, W. (2020). "Fumarate production with Rhizopus oryzae: Utilising the crabtree effect to minimise ethanol byproduct formation," Biotechnol Biofuels 13(1), 22. DOI: 10.1186/s13068-020-1664-8

Troiano, D., Orsat, V., and Dumont, M. (2020). "Status of filamentous fungi in integrated biorefineries," Renew. Sust. Energ. Rev. 117, article no. 109472. DOI: 10.1016/j.rser.2019.109472

Wu, X., Liu, Q., Deng, Y., Chen, X., Zheng, Z., Jiang, S., and Li, X. (2018). "Production of fumaric acid by bioconversion of corncob hydrolytes using an improved Rhizopus 
oryzae strain," Appl. Biochem. Biotechnol. 184(2), 553-569. DOI: 10.1007/s12010017-2554-9

Xing, H., Liu, H., Zhang, Y., Yu, Y., Huang, X., Xiao, Q., Deng, L., and Wang, F. (2020). "Capability enhancement of fumaric acid production by Rhizopus arrhizus through carbon-nitrogen sources coordination," Appl. Biochem. Biotechnol. 193, 1231-1237.

Zhang, K., Yu, C., and Yang, S.-T. (2015). "Effects of soybean meal hydrolysate as the nitrogen source on seed culture morphology and fumaric acid production by Rhizopus oryzae," Process Biochem. 50(2), 173-179. DOI: 10.1016/j.procbio.2014.12.015

Article submitted: September 7, 2021; Peer review completed: October 9, 2021; Revised version received and accepted: October 11, 2021; Published: October 21, 2021.

DOI: 10.15376/biores.16.4.8197-8204 